\title{
PENGARUH ACTIVE RECOVERY TERHADAP KADAR ASAM LAKTAT PADA MAHASISWA PROGRAM STUDI ILMU KEOLAHRAGAAN UNIVERSITAS NEGERI JAKARTA
}

\author{
Eko Juli Fitrianto \\ Syamsul Maarif \\ Fakultas Ilmu Olahraga Universitas Negeri Jakarta \\ Eko-Juli-Fitrianto@unj.ac.id \\ Syamsulmaarif750@gmail.com
}

\begin{abstract}
ABSTRAK
Asam laktat merupakan zat yang tertimbun di dalam tubuh setelah melakukan aktifitas dengan intensitas tinggi yang diakibatkan oleh system energi anaerob. Berdasarkan beberapa studi sebelumnya, penumpukan asam laktat setelah latihan secara efektif dapat diturunkan melalui metode active recovery.

Tujuan dari penelitian ini adalah untuk mengetahui pengaruh active recovery terhadap kadar asam laktat pada mahasiswa Program Studi llmu Keolahragaan Universitas Negeri Jakarta. Penelitian ini menggunakan metode eksperimen dengan one grup pre and post test design. Sampel penelitian berjumlah 10 orang yang akan didapat melalui teknik purposive sampling. Penelitian dilaksanakan di Gelanggang Olahraga Rawamangun dan Kampus B UNJ di Jakarta Timur pada bulan April hingga November tahun 2019. Berdasarkan hasil penelitian terdapat pengaruh active recovery terhadap kadar asam laktat pada mahasiswa Program Studi llmu Keolahragaan Universitas Negeri Jakarta.
\end{abstract}

Kata kunci: Active Recovery dan Asam Laktat

\section{ABSTRACT}

Lactic acid is a substance that is deposited in the body after carrying out activities with high intensity caused by the anaerobic energy system. Based on several previous studies, lactic acid buildup after exercise can effectively be reduced through active recovery methods.

The purpose of this study was to determine the effect of active recovery on lactic acid levels in students of the Sport science at the State University of Jakarta. This study uses an experimental method with one group pre and post test design. The research sample of 10 people who will be obtained through purposive sampling technique. The research was conducted at the Rawamangun Sports Center and Campus B UNJ in East Jakarta from April to November 2019. Based on the results of the study there was an effect of active recovery on lactic acid levels in students of the sport Science Program at the State University of Jakarta.

Keywords: Active Recovery and Lactic Acid

\section{PENDAHULUAN}

Asam laktat merupakan zat yang tertimbun di dalam tubuh setelah melakukan aktifitas dengan intensitas tinggi yang diakibatkan oleh system energi anaerob. Berdasarkan beberapa studi sebelumnya, penumpukan asam laktat setelah latihan secara efektif dapat diturunkan melalui metode active recovery.

Tujuan dari penelitian ini adalah untuk mengetahui pengaruh active recovery terhadap kadar asam laktat pada mahasiswa Program Studi llmu Keolahraan Universitas Negeri Jakarta. Penelitian ini menggunakan 
metode eksperimen dengan one grup pre and post test design. Sampel penelitian berjumlah 10 orang yang akan didapat melalui teknik purposive sampling. Penelitian dilaksanakan di Gelanggang Olahraga Rawamangun dan Kampus B UNJ di Jakarta Timur pada bulan April hingga November tahun 2019. Berdasarkan hasil penelitian terdapat pengaruh active recovery terhadap kadar asam laktat pada mahasiswa Program Studi llmu Keolahraan Universitas Negeri Jakarta.

Asam Laktat.

Andre Tjie Wijaya (2014), Asam laktat merupakan produk hasil metabolisme karbohidrat tanpa menggunakan oksigen (metabolisme anaerobik). Asam laktat diproduksi di sel otot saat suplai oksigen tidak mencukupi untuk menunjang produksi energi.

Giri Wiarto (2013), asam laktat adalah konversi dari asam piruvat ketika melakukan aktifitas fisik yang cepat. Asam piruvat merupakan senyawa kimia yang berasal dari glukosa melalui glikolisis. Dapat dikatakan asam laktat terbentuk dari proses metabolisme karbohidrat yang berjalan tidak melibatkan oksigen dan dilakukan dalam aktifitas fisik yang cepat, karbohidrat merupakan senyawa yang kompleks dan akan diurai oleh tubuh menjadi glukosa, glukosa menjadi bahan utama pembakaran, asam piruvat terbentuk dari proses glikolisis yang merupakan proses pembakaran glukosa, kemudian asam piruvat akan di konversi menjadi asam laktat, dalam hal ini ada rangkaian sistem energi yang terjadi pada proses pembentukan asam laktat.

Asam laktat terbentuk dari hasil akhir proses sistem energi glikolisis-lactic acid, sistem energi ini menggunakan glukosa, yang di dapat dari pemecahan karbohidrat yang berasal dari bahan makanan, namun dalam proses ini digunakan lebih awal saat aktifitas fisik sehingga tidak menggunakan oksigen, karbohidrat merupakan sumber energi yang kompleks sehingga harus diubah menjadi jenis yang sederhana, dan dapat segera dipergunakan dalam bentuk glukosa, dalam proses glikolisis-lactid acid, glukosa adalah sumber utama dalam pembentukan energy dan dalam prosesnya tidak menggunakan oksigen, sehingga asam laktat terbentuk sebagai hasil akhirnya, oleh karena itu sistem ini dinamakan sistem asam laktat (Fox, 1984).

Prof. Drs. Moeljono Wiryo Soputro dan Drs. Slamet Suherman juga menjelaskan, Dengan pemecahan glikogen yang tidak memerlukan oksigen, dapat juga dihasilkan sejumlah energi yang dipakai untuk resintesis ATP. Karena tidak memakai oksigen, maka sebagai hasil akhir pemecahan glikogen akan dihasilkan asam laktat (Moeljono dan Slamet, 1993).

Berdasarkan kutipan tersebut pembentukan energi dengan pemecahan glikogen dapat dilakukan ada tidak menggunakan oksigen dan ada yang menggunakan oksigen, hal ini akan membedakan hasil akhir dari proses pembakarannya, jika pembakaran glukosa tanpa menggunakan oksigen tubuh akan mengeluarkan asam laktat sebagai hasil pembakarannya, jika menggunakan oksigen tubuh tidak menghasilkan asam laktat.

Sadoso Sumosadjuno (1994), jika seseorang melakukan latihan-latihan olahraga pada keadaan ini (asam laktat yang menumpuk), maka hutang oksigen di dalam tubuh akan menjadi lebih banyak dan akan makin banyak terkumpul asam laktat di dalam sel, kumpulan dari asam laktat yang banyak akan menghalangi, kemudian menghentikan sama sekali produksi ATP (Adenosin Tri Phospat). ATP merupakan suatu ikatan yang begitu penting pada penghasilan dan penggunaan energi, dan ikut serta hampir setiap macam reaksi yang menghasilkan energi yang perlu untuk menopang suatu aktifitas (Wiarto, 2013).

Tubuh pada kondisi tersebut mengalami kehilangan cadangan oksigen di dalam tubuh, Tubuh yang normal memiliki 2 liter cadangan oksigen yang dapat digunakan untuk metabolisme (Wiarto, 2013), cadangan oksigen digunakan saat kita melakukan aktifitas fisik anaerobik, jika cadangan oksigen dipakai secara terusmenerus, maka tubuh akan menghasilkan asam laktat saat aktifitas fisik dengan intensitas tinggi, kemudian jika asam laktat telah menumpuk, tubuh tidak dapat menghasilkan ATP hal ini disebabkan karena asam laktat akan menghalangi 
produksi ATP, sehingga tubuh tidak memiliki energi untuk aktifitas, dan langsung akan menurunkan intensitasnya bahkan dapat menghentikan aktifitas fisiknya jika sudah mengalami kondisi tersebut.

Namun asam laktat bukanlah sampah yang tidak berguna, Jhon Shepher menjelaskan bahwa asam laktat bukan merupakan produk limbah. selama pemulihan, ketika ada jauh lebih banyak pasokan oksigen, asam laktat kehilangan dua hidrogen dan kembali menjadi asam piruvat, dan digunakan sebagai sumber energi (Sepherd, 2006).

\section{Active Recovery.}

Merupakan Proses pemulihan dengan melakukan aktivitas fisik namun dalam kadar volume dan intensitas yang ringan. Seperti melakukan joging setelah melakukan latihan atau pertandingan yang berintensitas tinggi.

Berarti active recovery dilakukan dengan melakukan aktifitas fisik yang ringan, hal ini harus segera dilakukan setelah kita melakukan aktifitas fisik dengan intensitas yang tinggi, agar kondisi tubuh kita berada pada kondisi sebelum melakukan aktifitas fisik.

Kutipan diatas menjelaskan, active recovery dilakukan dengan aktivitas yang ringan, berjalan, bersepeda atau berlari dapat digunakan sebagai active recovery, saat active recovery intensitas akan menentukan dalam proses penghapusan asam laktat, aktifitas yang harus dilakukan harus aktifitas yang ringan dan dilakukan pada kisaran waktu 20 menit agar asam laktat terurai kembali (Barbora, 2012).

Penyingkiran asam laktat pada individu yang tidak terlatih akan lebih optimal apabila dilakukan dengan aktifitas fisik pada intensitas antara 30-45\% $\quad \mathrm{VO}_{2}$ MAX, sedangkan bagi atlet atau individual dilakukan dengan aktifitas fisik pada intensitas antara $50-56 \% \mathrm{VO}_{2} \mathrm{MAX}$.

Adanya pembeda antara seseorang yang terlatih dengan tidak terlatih, dalam hal ini proses pemulihan aktif akan dipengaruhi dengan intensitas aktifitas yang kita lakukan, pada proses pemulihan aktif seseorang yang tidak terlatih akan lebih optimal dengan melakukan aktifitas fisik dengan intensitas $30-45 \%$ dari ambilan oksigen maksimal, sedangkan seseorang yang terlatih harus melakukan aktifitas fisik dengan intensitas 50-56\% dari ambilan oksigen maksimal, hal ini dianjurkan agar proses pemulihan penurunan kadar asam laktat lebih optimal sehingga proses penghapusan asam laktat akan lebih cepat (Widyanto, 2007).

Asam laktat akan di oksidasi saat otot rangka bekerja dengan intensitas rendah, aliran darah akan membawa asam laktat menuju ke hati dan saat itu juga asam laktat akan diubah menjadi glukosa, dalam hal ini active recovery akan lebih efektif menurunkan kadar asam laktat karena dengan melakukan aktifitas yang ringan tubuh akan bekerja secara menyeluruh sehingga distribusi oksigen akan cepat sampai ke organ dan distribusi asam laktat ke organ hati akan berjalan lancar, dengan kecukupan oksigen serta cepatnya asam laktat dibawa kehati, proses oksidasi akan berjalan cepat sehingga asam laktat akan cepat berkurang (Menzies, 2010).

\section{METODE}

Metode penelitian yang akan digunakan adalah metode eksperimen dengan One Group Pre-Test and Post-Test Design. Adapun yang menjadi variable bebas adalah active recovery dan yang menjadi variable terikat adalah kadar asam laktat.

Pengumpulan data digunakan sebagai data penelitian adalah data yang diperoleh melalui pengukuran kadar asam laktat. Untuk meningkatkan kadar asam laktat tubuh, subjek penelitian diberikan aktifitas anaerobic maksimal dengan melakukan lari $400 \mathrm{~m}$. Setelah itu subjek penelitian melakukan jalan santai 20 menit untuk sebagai perlakuan active recovery. Pengambilan data pengukuran asam laktat dilakukan sebelum melakukan aktivitas, setelah melakukan lari $400 \mathrm{~m}$ dan setelah melakukan active recovery.

\section{HASIL PENELITIAN}

Berdasarkan pengumpulan data digunakan sebagai data penelitian yang diperoleh dari tes awal dan tes akhir kadar asam laktat dalam darah, berdasarkan pengamatan dari hasil efek kerja recovery 
active terhadap penurunan kadar asam laktat. Adapun data-data tersebut dapat diuraikan sebagai berikut.

\begin{tabular}{ccc}
\hline \multirow{2}{*}{ Variabel } & \multicolumn{2}{c}{$\begin{array}{c}\text { Kadar Asam Laktat } \\
(\mathbf{m m o l} / \mathbf{L})\end{array}$} \\
\cline { 2 - 3 } & $\begin{array}{c}\text { Lari } \\
\mathbf{4 0 0} \mathbf{~ m}\end{array}$ & $\begin{array}{c}\text { Active } \\
\text { Recovery }\end{array}$ \\
\hline Nilai Terendah & 4.5 & 2 \\
\hline Nilai Tertinggi & 6.1 & 2.8 \\
\hline Mean & 5.2 & 2.26 \\
\hline Standar Deviasi & 0.48 & 0.24 \\
\hline $\begin{array}{c}\text { Standar } \\
\text { Kesalahan Mean }\end{array}$ & 0.16 & 0.08 \\
\hline
\end{tabular}

Data tes awal Kadar asam laktat pada kelompok recovery active diperoleh nilai terendah $4,5 \mathrm{mmol} / \mathrm{L}$ dan nilai tertinggi 6,1 $\mathrm{mmol} / \mathrm{L}$ dengan rata-rata $(\mathrm{X} 1)$ 5,2 $\mathrm{mmol}$, simpang baku $(\mathrm{Sx} 1)=0,48$ dan standar kesalahan mean $($ SEmx 1$)=0,16$.

Data tes akhir Kadar asam laktat pada kelompok recovery active diperoleh nilai terendah $2.0 \mathrm{mmol} / \mathrm{L}$ dan nilai tertinggi 2.8 $\mathrm{mmol} / \mathrm{L}$ dengan rata-rata $(\mathrm{X} 1) 2,26 \mathrm{mmol} / \mathrm{L}$, simpang baku $(\mathrm{Sx} 2)=0,24$ dan standar kesalahan mean $(\mathrm{SEmx} 1)=0.08$.

Dari hasil tes awal dan tes akhir kadar asam laktat pada kelompok recovery active yang diperoleh dan telah diuraikan tersebut dapat digambarkan kedalam grafik histogram dibawah ini.
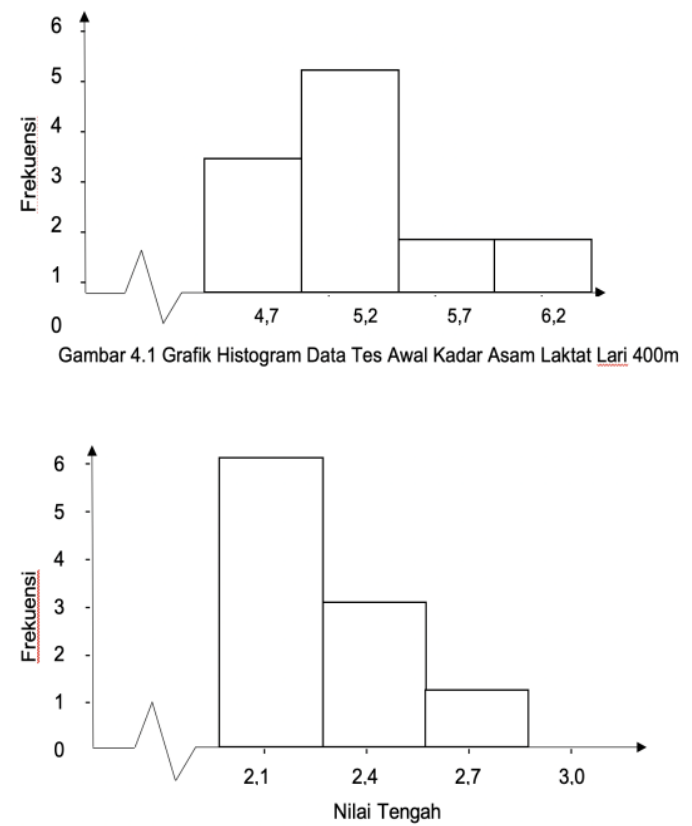

Gambar 4.2 Grafik Histogram Data Tes Akhir Kadar Asam Laktat Active Recovery
Hasil analisis dari tes awal dan tes akhir kadar asam laktat dengan menggunakan efek kerja recovery active diperoleh nilai rata-rata $(\mathrm{MD})=2,94$, simpang baku $(\mathrm{SD})=0,39$ dan standar kesalahan mean $\left(\mathrm{SE}_{\mathrm{MD}}\right)=0,13$, nilai tersebut menjadi t-hitung diperoleh $=22,61$. Kemudian hasil tersebut diujikan dengan $\mathrm{t}$ tabel pada derajat kebebasan $(\mathrm{dk})=\mathrm{n}-1=$ $10-1=9$ dengan taraf kepercayaan $(\alpha)=$ 0,05 diperoleh nilai kritis t-tabel $=2,262$. Dengan demikian nilai t-hitung lebih besar dari $\mathrm{t}$-tabel $(\mathrm{t}$-hitung $=22,61>\mathrm{t}$-tabel $=$ 2,262). Berdasarkan analisis data tersebut dapat disimpulkan hipotesis nol (H0) ditolak, hipotesis kerja (H1) diterima, berarti efek kerja recovery active dapat menurunkan kadar asam laktat.

\section{PEMBAHASAN}

Berdasarkan beberapa temuan penelitian terdahulu, dapat dipahami bahwa asam laktat adalah zat yg diproduksi di sel otot ketika melakukan aktifitas intensitas tinggi melalui pemecahan glukosa untuk menjadi energi. Peningkatan kadar asam laktat direspon dengan tubuh dengan mengeluarkan asam laktat yg ada di otot untuk digunakan oleh organ yang lain sebagai upaya untuk mereduksi tingginya kadar asam laktat di otot. Untuk mempercepat penurunan kadar asam laktat tubuh memerlukan loksigen untuk mengoksidasi asam laktat yang dilakukan melalui aktifitas recovery, salah satunya adalah active recovery.

Pada hasil penelitian diketahui bahwa terjadi penurunan kadar asam laktat setelah melakukan active recovery. Dari uji t-tabel pada derajat kebebasan $(\mathrm{dk})=\mathrm{n}-1=10-1$ $=9$ dengan taraf kepercayaan $(\alpha)=0,05$ diperoleh nilai kritis t-tabel $=2,262$. Dengan demikian nilai t-hitung lebih besar dari ttabel (t-hitung $=22,61>\mathrm{t}$-tabel $=2,262$ ). Berdasarkan analisis data tersebut dapat disimpulkan hipotesis nol (H0) ditolak, hipotesis kerja (H1) diterima, yang berarti bahwa terdapat efek kerja recovery active dalam menurunkan kadar asam laktat.

Berdasarkan kajian teori dan penemuan penelitian sebelumnya, diketahui bahwa hal ini terjadi karena terpenuhinya kebutuhan oksigen untuk mengoksidasi asam laktat 
menjadi energi pada saat melakukan active recovery. Selain itu dengan penurunan intensitas pada active recovery membantu melancarkan peredaran darah dan hal membantu transport asam laktat untuk keluar dari otot.

\section{KESIMPULAN}

Berdasarkan hasil analisis data, deskripsi, pengujian hasil penelitian, dan pembahasan, dapat diambil kesimpulan bahwa terdapat pengaruh Active Recovery terhadap penurunan kadar asam laktat Pada Mahasiswa Program Studi Ilmu Keolahragaan Universitas Negeri Jakarta.

\section{REFERENSI}

Andre Tjie Wijaya, Asam Laktat: Nutrisi, 2014, p.1 (http://www.kerjanya. net/faq/5061-asam-laktat.html.

Agus Sumarsono, "Pengaruh Mekanis Masase Lokal Extrimitas Bawah Sebagai Pemulihan Pasif Terhadap Kecepatan Lari," Jurnal Kesehatan Olahraga, Mei 2013 (1), hal.1-5.

Barbora Strejcová and Renata Konopková, "The Effect Of Active Recovery, Cold Water Immersion And Passive Recovery On Subsequent Knee Extension And Flexion Strength," Acta Univ. Palacki. Olomuc.,
Gymn, Desember 2012, 42, hal. 3947.

Edwar L. Fox, Sport Physiology, Philadelphia :W.B. Sounders Company, 1979

Moeljono Wiryo Soputro dan Slamet Suherman, Materi Pokok Kesehatan Olahraga, Jakarta: Departemen Pendidikan dan Kebudayaan, 1993.

Peter Janssen, Lactate Threshold Training, Europe : Human Kinetics, 2001.

Paul Menzies et. al., Blood Lactate Clearance During Active Recovery After An Intense Running Bout Depends On The Intensity Of The Active Recover, Journal of Sports Sciences, March 2010 (28), hal. 975-982.

Sumosardjuno, Sadoso, Pengetahuan Praktis Kesehatan dalam Olahraga 2. Jakarta: PT. Gramedia Pustaka Utama, 1994.

Wiarto, Giri, Fisiologi dan Olahraga, Yogyakarta : Graha Ilmu, 2013.

Widiyanto, Latihan Fisik Dan Asam Laktat, Universitas Negeri Yogyakarta., MEDIKORA, April 2007 (1), hal. 61-79. 